\title{
ELABORAÇÃO E IMPLANTAÇÃO DO MAPA DE RISCOS AMBIENTAIS PARA PREVENÇÃO DE ACIDENTES DO TRABALHO EM UMA UNIDADE DE TERAPIA INTENSIVA DE UM HOSPITAL UNIVERSITÁRIO*
}

Maria Cecilia Cardoso Benatti**

Vera Médice Nishide***

BENATTI, M.C.C.; NISHIDE, V.M. Elaboração e implantação do mapa de riscos ambientais para prevenção de acidentes do trabalho em uma unidade de terapia intensiva de um hospital universitário. Rev.latinoam.enfermagem, Ribeirão Preto, v. 8, n. 5, p. 13-20, outubro 2000.

O objetivo deste trabalho é trazer para o âmbito da saúde do trabalhador questionamentos relativos aos riscos ambientais a que estão expostos os trabalhadores de uma Unidade de Terapia Intensiva de um Hospital Universitário. Para tanto, elaborouse um instrumento em que os trabalhadores envolvidos descreviam os riscos ambientais da Unidade de Terapia Intensiva. Como resultado comprovou-se no ambiente a existência de riscos biológicos, físicos, químicos, ergonômicos e riscos de acidentes do trabalho. Implantou-se a seguir o mapa de risco da UTI.

UNITERMOS: acidentes do trabalho, programas de assistência a saúde dos trabalhadores

\section{INTRODUÇÃO}

A preocupação com a questão da saúde dos trabalhadores hospitalares no Brasil iniciou-se na década de 70, quando pesquisadores da Universidade de São Paulo enfocaram a saúde ocupacional em trabalhadores hospitalares.

GOMES (1974), estudando a saúde ocupacional em hospital, citou que em 1971 ocorreram 4.468 acidentes do trabalho em estabelecimentos hospitalares brasileiros.

FRANCO (1981) estudou 26 grupos ocupacionais de trabalhadores hospitalares no ano de 1977 captando queixas e doenças relacionadas com o processo de trabalho, tais como: doenças infectocontagiosas, lombalgias, doenças alérgicas, fadigas e acidentes do trabalho.

SILVA (1988), analisando 1.506 acidentes do trabalho no Hospital das Clínicas da Universidade de São Paulo, encontrou lacerações e ferimentos, contusões e torções como as mais freqüentes causas de afastamento do trabalho.

ALEXANDRE (1993) constatou que as dores nas costas representam um sério e expressivo problema para os trabalhadores de enfermagem hospitalar. A autora atribuiu como nexo causal para as lombalgias o transporte e a movimentação de pacientes, a postura inadequada e estática e mobiliário e equipamentos também inadequados.

Na literatura mundial, CARRASCAL (1991) referiu 25 casos de pessoal hospitalar com HIV positivo cujo único fator de risco foi a exposição ocupacional. CARDO (1995) alertou que já são 46 os profissionais de saúde comprovadamente contaminados com o vírus HIV em acidentes hospitalares. Desses, 20 já desenvolveram AIDS.

No Brasil, MACHADO et al. (1992), investigando o risco de infecção pelo vírus da imunodeficiência humana (HIV) em profissionais da saúde, constataram que de 36 casos de acidentes estudados 17 foram por perfuração com agulhas contaminadas e um por ampola quebrada, totalizando $50 \%$ das ocorrências. Os resultados foram negativos quanto à soroconversão.

PITTA (1990) associou ao trabalho doenças genitourinárias, psicossomáticas e osteomusculares encontradas em uma população de trabalhadores de um

\footnotetext{
* Trabalho apresentado no $4^{\text {th }}$ International Conference on Occupational Health for Health Care Workers em Montreal - Canadá, 1999

** Enfermeira - Professor Assistente Doutor - Departamento de Enfermagem da Faculdade de Ciências Médicas da Universidade Estadual de Campinas - UNICAMP

*** Enfermeira - Diretora da Unidade de Terapia Intensiva do Hospital de Clínicas da UNICAMP e Mestranda do Departamento de Enfermagem - FCM/UNICAMP
} 
hospital geral de 400 leitos no município de São Paulo.

BENATTI (1997) constatou em uma população

de 1.218 trabalhadores uma incidência acumulada de $8,2 \%$ de acidentes. No estudo caso-controle a autora constatou que os acidentados têm falta de tempo para lazer, não têm esquema de vacinação completo (dupla adulto, Hepatite B) e adotam posturas cansativas e forçadas durante o trabalho.

A partir desses últimos estudos, justificou-se proceder ao presente trabalho em uma unidade de terapia intensiva de um hospital universitário com o objetivo de trazer para o âmbito da saúde do trabalhador questionamentos relativos aos riscos ambientais existentes no local de trabalho e propor soluções preventivas através do uso do mapa de riscos proposto pela legislação vigente (Norma regulamentadora $\mathrm{n}^{\circ} 5$ "CIPA" Portaria $n^{\circ} 8$, de 23/02/1999 - Ministério do Trabalho). O mapeamento de riscos ambientais é uma técnica empregada para coletar o maior número possível de informações sobre os riscos existentes no ambiente de trabalho, levando em conta a avaliação dos funcionários. O Mapa de Riscos permite fazer um diagnóstico da situação de segurança e saúde do trabalho nas empresas com a finalidade de estabelecer medidas preventivas (CAMPOS, 1999).

\section{METODOLOGIA}

\subsection{Considerações iniciais}

A Unidade de Terapia Intensiva - UTI - do Hospital de Clínicas - HC - da Universidade Estadual de Campinas - UNICAMP- está localizada no segundo andar do prédio central.

A área física é de aproximadamente $900 \mathrm{~m} 2$ onde 24 leitos/boxes estão distribuídos em cinco postos, sendo 18 leitos ativos. Além da área de internação, há também a área administrativa, os corredores, a sala de equipamentos, o auditório, os sanitários, os vestiários e o arsenal de material de consumo.

$\mathrm{O}$ estudo foi realizado no período de março a maio de 1998.

\subsection{População}

A população foi composta pela equipe multidisciplinar permanente da UTI, que trabalha com atividades assistenciais e administrativas em uma unidade de internação de alta complexidade (vide Tabela 1). Neste período foram entregues 84 formulários, sendo devolvidos 62. Destes, seis foram excluídos por preenchimento incompleto, totalizando 56 formulários para a análise final (66,7\%) que compuseram a população da amostra estudada.

\subsection{Instrumento de coleta de dados}

Optou-se por um formulário aplicado pelas pesquisadoras aos trabalhadores da equipe multidisciplinar da UTI solicitando categoria profissional, sexo, idade e contendo duas questões abertas, visando a identificação dos principais riscos de acidentes aos quais o trabalhador se expõe e também solicitando sugestões para melhoria do ambiente de trabalho quanto ao risco de acidentes apontados na questão anterior. A análise dos dados coletados foi realizada manualmente por uma das autoras.

\subsection{Aspectos éticos}

A participação dos trabalhadores foi de forma voluntária, respeitando-se o código de ética dos profissionais de enfermagem publicado pelo CONSELHO FEDERAL DE ENFERMAGEM (1993). Também foi garantida a possibilidade de retorno dos resultados da pesquisa aos trabalhadores e preservado o segredo quanto aos identificadores individuais.

\section{RESULTADOS E DISCUSSÃO}

\subsection{Identificação da população}

O formulário, em sua parte introdutória, contém dados sobre algumas características dos trabalhadores da UTI. Foram levantados a categoria profissional, o sexo e a idade.

Tabela 1 - Distribuição dos trabalhadores de UTI segundo a participação por categoria profissional, Campinas, São Paulo, 1998

\begin{tabular}{lccc}
\hline CATEGORIA & \multicolumn{2}{c}{ PARTICIPANTES } & RESULTADOS \\
PROFISSIONAL & $\mathbf{N}^{\mathbf{a}}$ & $\mathrm{N}^{\mathbf{0}}$ & $\mathbf{\%}$ \\
\hline Auxiliar hospitalar & 03 & 03 & 100,0 \\
(escolta) & & & 100,0 \\
Oficial Unidade & 01 & 01 & 75,0 \\
Fisioterapeuta & 04 & 03 & 72,4 \\
Técnico/Auxiliar & 29 & 21 & 64,3 \\
Enfermagem & & 18 & 53,3 \\
Enfermeiro & 28 & 18 & 50,0 \\
Médico & 15 & 08 & \\
Auxiliar limpeza & 04 & 02 & $\mathbf{6 6 , 7}$ \\
hospitalar & & & \\
\hline Total & $\mathbf{8 4}$ & $\mathbf{5 6}$ & \\
\hline
\end{tabular}

Pela análise da Tabela 1, verifica-se uma participação de $66,7 \%$ dos trabalhadores envolvidos, demonstrando o interesse e a valorização desta pesquisa pelos trabalhadores da UTI. 
Quanto ao sexo dos trabalhadores entrevistados, constatou-se $46(82,1 \%)$ mulheres e $10(17,9 \%)$ homens.

A faixa etária dos trabalhadores da UTI foi reunida na Tabela 2.

Tabela 2 - Distribuição dos trabalhadores de UTI, segundo faixa etária, Campinas, São Paulo, 1998

\begin{tabular}{lcc}
\hline \multicolumn{1}{c}{ Faixa Etária } & $\mathbf{N}^{\mathbf{0}}$ & $\mathbf{\%}$ \\
\hline 20 ---- 30 & 20 & 35,7 \\
30 -- 40 & 26 & 46,4 \\
40 ---- 50 & 09 & 16,1 \\
50 --- 60 & 01 & 1,8 \\
\hline Total & $\mathbf{5 6}$ & $\mathbf{1 0 0 , 0}$ \\
\hline
\end{tabular}

A distribuição dos trabalhadores da UTI por faixa etária demonstrou a predominância dos 30 aos 40 anos $(46,4 \%)$ e também a totalidade dos trabalhadores em plena idade produtiva onde um acidente do trabalho tem elevado custo social.

\subsection{Principais riscos de acidentes no ambiente de trabalho \\ Procurou-se investigar os riscos de acidentes} identificados pelos trabalhadores no decorrer do processo de trabalho (Figura 1).

\begin{tabular}{|l|c|c|c|c|}
\hline \multirow{2}{*}{ RIS COS APONTADOS } & \multicolumn{2}{c|}{ RESP OSTA } & \multicolumn{2}{c|}{ CLASSIFICAÇ̃̃ } \\
\cline { 2 - 5 } & $\mathbf{N}^{\mathbf{0}}$ & $\mathbf{0}$ & GRUPO & \multicolumn{1}{c|}{ RISCO } \\
\hline Material perfurocortante & 43 & 76,8 & 5 & acidente \\
Chão molhado e escorregadio & 29 & 51,8 & 5 & acidente \\
Esforço fisico/postura não ergonômica & 20 & 35,7 & 4 & ergonômnico \\
Planta fisica inadequada & 14 & 25,0 & 5 & acidente \\
Contato com fluido corporal & 13 & 23,2 & 3 & biológico \\
Tomada e ponto de antena insuficiente & 12 & 21,4 & 5 & acidente \\
Armazenamento de soro inadequado & 09 & 16,1 & 5 & acidente \\
Equipamento ultrapassado e com falta de manutenção & 08 & 14,3 & 5 & acidente \\
Iluminação insuficiente & 07 & 12,5 & 5 & acidente \\
Limpeza e higiene dos sanitários insuficiente & 07 & 12,5 & 3 & biológico \\
Temperatura instável e pouca circulação de ar & 05 & 8,9 & 1 & fisico \\
Radiação ionizante (Raio X no leito) & 04 & 7,1 & 1 & fisico \\
Atitude automática e ritmo excessivo durante procedimentos & 03 & 5,4 & 4 & ergonômico \\
Inadequada eliminação e tratamento do lixo & 02 & 3,6 & 5 & acidente \\
Inalação de produtos químicos & 02 & 3,6 & 2 & químico \\
\hline
\end{tabular}

Figura 1 - Distribuição dos riscos de acidentes apontados pelos trabalhadores da UTI de acordo com classificação por grupo de risco, proposta pela N.R. n 5-CIPA, Campinas, São Paulo, 1998

Nos estudos de SANTOS et al. (1989); SOUZA \& VIANNA (1993); SILVA et al. (1995) a primeira causa de acidente também foi por material perfurocortante.

BENATTI (1997), no mesmo hospital deste estudo, constatou o uso abusivo de lâminas em atividades não necessárias e o abandono de material descartável usado em lugares inadequados (balcões, bandejas, camas e pisos).

No acidente provocado por chão molhado e escorregadio, planta física inadequada e outros riscos apontados do grupo 5 (acidente), observa-se que não são riscos específicos da área hospitalar, existindo ocorrências similares em indústrias e atividades comerciais, com grande impacto nas condições de saúde dos trabalhadores.

Quanto ao esforço físico e postura não ergonômica, são agentes agressivos cuja fonte tem ação em pontos específicos do ambiente (leitos/boxes).

ALEXANDRE (1993) confirmou que a postura incorreta devido a condições de trabalho leva à fadiga muscular e a lesões na coluna vertebral. Em suas conclusões, relatou que os trabalhadores de enfermagem referem que as dores nas costas são produzidas principalmente pelo transporte e a movimentação de pacientes e pela manutenção de posturas inadequadas e estáticas.

No que se refere ao contato com fluido corporal é um risco biológico muito encontrado no ambiente hospitalar. A contaminação por meio de secreções e eliminações é considerada risco biológico para o trabalhador (SEGURANÇA..., 1999).

O número de tomadas e pontos de antena insuficientes, pode levar o trabalhador ao uso de extensões e conexões, que trazem riscos de curto-circuitos, choques elétricos, incêndios, queimaduras e até de acidentes fatais.

GIAMPAOLI (1985), constatou que a iluminação adequada no local de trabalho proporciona um ambiente 
agradável e diminui as possibilidades de acidentes.

As condições térmicas do local de trabalho devem proporcionar conforto aos trabalhadores, com temperatura mantida entre 24 e $26^{\circ} \mathrm{C}$, estável e igual em todos os compartimentos, evitando deslocamento de ar excessivo e conservando a umidade relativa em níveis de 40 a 60\% (BRASIL. Ministério da Saúde,1995; WEDEL et al., 1995).

Em UTI o ar-condicionado e o aquecimento devem ser previstos visando conforto para os pacientes e equipe de trabalho, com sistemas de filtragem apropriados. A qualidade do ar deve ser segura, satisfatória e mantida estável durante todo o tempo. São exigidas no mínimo seis trocas de ar por hora, sendo que duas devem ser com ar externo (BRASIL. Ministério da Saúde, 1995; WEDEL et al., 1995).

Quanto às radiações ionizantes, são ocasionadas pelo aparelho de Raios-X portátil, sendo a exposição diária e periódica, porém não contínua.

\subsection{Apresentação de sugestões para melhoria do ambiente quanto aos riscos apontados}

Foi proposto aos trabalhadores que apresentassem sugestões para melhoria do ambiente (Figura 2).

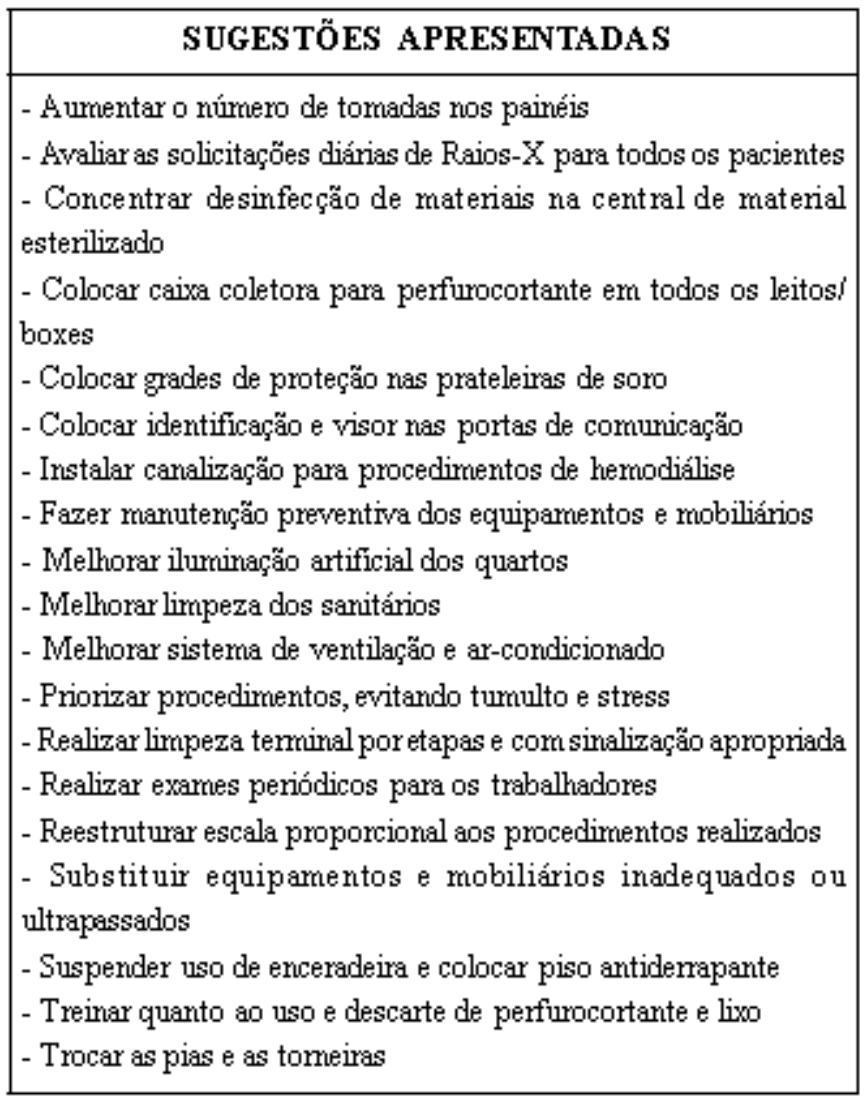

Figura 2 - Sugestões apresentadas pelos trabalhadores de UTI quanto aos riscos de acidentes apontados, Campinas, São Paulo, 1998
As respostas obtidas na Figura 2 demonstram o quanto as experiências, percepções e opiniões dos próprios trabalhadores devem ser levadas em consideração na análise do ambiente e do processo de trabalho.

COSTA (1981), ao estudar os acidentados do trabalho, constatou que os acidentes estão sempre ligados às más condições de trabalho, à ausência de equipamentos para sua execução e ao aumento da intensidade do trabalho. Os trabalhadores entrevistados também apontaram estes problemas.

\subsection{Soluções preventivas baseadas nos riscos} ocupacionais apontados pelos trabalhadores através do mapa de risco ambiental

Nesta etapa do trabalho, após levantamento dos riscos apontados pelos trabalhadores (Figura 1) e sugestões apresentadas pelos mesmos (Figura 2), elaborou-se o mapa de risco (Figura 3 a 9), previsto pela NR 5 (SEGURANÇA..., 1999).

\begin{tabular}{|c|c|c|}
\hline $\begin{array}{l}\text { RISCOS } \\
\text { FÍsICOS }\end{array}$ & $\begin{array}{c}\text { FONTE } \\
\text { GERAD ORA }\end{array}$ & REC OMENDAÇÕES \\
\hline $\begin{array}{l}\text { Te mperat ura } \\
\text { instávele pouca } \\
\text { circulação de ar }\end{array}$ & $\begin{array}{l}\text { Unidade fechada } \\
\text { dependendo de ar- } \\
\text { condicionado e } \\
\text { ventilação artificial }\end{array}$ & $\begin{array}{l}\text { Melhorar sistema de } \\
\text { circulação de ar e manter } \\
\text { termperatura estabilizada }\end{array}$ \\
\hline $\begin{array}{l}\mathrm{R} \text { a d i a çã o } \\
\text { ionizante }\end{array}$ & Raios-X no leito & $\begin{array}{l}\text { Avaliar adequadamente, } \\
\text { diminuir o número de } \\
\text { solicitações e fazer } \\
\text { proteção radio lógica nos } \\
\text { postos }\end{array}$ \\
\hline
\end{tabular}

Figura 3 - Classificação dos riscos físicos apontados (grupo 1: cor verde) pelos trabalhadores de UTI, sua principal fonte geradora e recomendações, Campinas, São Paulo,1998

\begin{tabular}{|l|l|l|}
\hline \multicolumn{1}{|c|}{$\begin{array}{c}\text { RISCOS } \\
\text { QUIMIC OS }\end{array}$} & $\begin{array}{c}\text { FONTE } \\
\text { GERAD ORA }\end{array}$ & REC OMENDAÇÕES \\
\hline $\begin{array}{l}\text { Inalação de } \\
\text { prod u t os } \\
\text { químicos }\end{array}$ & $\begin{array}{l}\text { Pre paro de medi- } \\
\text { caçes }\end{array}$ & Utilizar máscaras \\
& & Não reutilizar frascos \\
\hline
\end{tabular}

Figura 4 - Classificação dos riscos químicos (grupo 2: cor vermelha) apontados pelos trabalhadores de UTI, sua principal fonte geradora e recomendações, Campinas, São Paulo, 1998 


\begin{tabular}{|c|c|c|}
\hline $\begin{array}{c}\text { RISCOS } \\
\text { BIOLÓGICOS }\end{array}$ & $\begin{array}{c}\text { FONTE } \\
\text { GERADORA }\end{array}$ & REC OMENDAÇÕES \\
\hline $\begin{array}{l}\text { Contato com } \\
\text { fluido corporal }\end{array}$ & $\begin{array}{l}\text { Espirro de secre- } \\
\text { ções durante os } \\
\text { procedimentos, } \\
\text { reaproveitarrento } \\
\text { de frascos, esva- } \\
\text { ziar porto-vac, } \\
\text { aspirar pacientes }\end{array}$ & $\begin{array}{l}\text { Aumentar a atenção e o } \\
\text { treinamento } \\
\text { Usar óculos e máscaras } \\
\text { Utilizar materiais mais } \\
\text { Seguros } \\
\text { Fazer exames periódicos }\end{array}$ \\
\hline $\begin{array}{l}\text { Limpezae higiene } \\
\text { dos sanitánios }\end{array}$ & Odor, sujidade & $\begin{array}{l}\text { Aumentar a frequiência da } \\
\text { limpeza }\end{array}$ \\
\hline
\end{tabular}

Figura 5 - Classificação dos riscos biológicos (grupo 3: cor marrom) apontados pelos trabalhadores de UTI, sua principal fonte geradora e recomendações, Campinas, São Paulo, 1998

\begin{tabular}{|c|c|c|}
\hline $\begin{array}{c}\text { RISCOS } \\
\text { ERGONÔMICOS }\end{array}$ & $\begin{array}{c}\text { FONTE } \\
\text { GERADORA }\end{array}$ & RECOMENDAÇÕES \\
\hline $\begin{array}{l}\text { Esfơço fisicolpostura } \\
\text { não ergonômica }\end{array}$ & $\begin{array}{l}\text { Peso dos } \\
\text { pacientes } \\
\text { Manivela das } \\
\text { carnas } \\
\text { Colocação de } \\
\text { placa Raios-X } \\
\text { Transportes } \\
\text { monitores }\end{array}$ & $\begin{array}{l}\text { Usar equipamentos que } \\
\text { auxiliem o traballhador } \\
\text { Substituir por carnas } \\
\text { hidráulicas } \\
\text { Colocar camas corn } \\
\text { suporte de placa Raios-X } \\
\text { Monitores fixos por leito }\end{array}$ \\
\hline $\begin{array}{l}\text { Atitude automática e } \\
\text { ritmo excessivo }\end{array}$ & $\begin{array}{l}\text { Excesso de } \\
\text { procedimentos }\end{array}$ & $\begin{array}{l}\text { Proporcionar número de } \\
\text { trabalhadores de acordo } \\
\text { com procedimentos }\end{array}$ \\
\hline
\end{tabular}

Figura 6 - Classificação dos riscos ergonômicos (grupo 4: cor amarela) apontados pelos trabalhadores, sua principal fonte geradora e recomendações, Campinas, São Paulo, 1998

\begin{tabular}{|c|c|c|}
\hline RISC OS DE ACIDENTES & FONTE GERADORA & REC OMENDAÇÕES \\
\hline Material perfurocortante & $\begin{array}{l}\text { Uso indevido de lâminas bisturi } \\
\text { Abandono em locais inadequados }\end{array}$ & $\begin{array}{l}\text { Limitaros materiais cortantes, substituí-los por } \\
\text { tesoura } \\
\text { Treinar a equipe } \\
\text { Colocar caixa perfurocortante em todos os } \\
\text { boxes }\end{array}$ \\
\hline Chão molhado e escorregadio & $\begin{array}{l}\text { Limpeza terminal nos boxes, postos e } \\
\text { corredores }\end{array}$ & $\begin{array}{l}\text { Colocar piso antiderrapante } \\
\text { Limpar em etapas } \\
\text { Sinalizar durante a limpeza } \\
\text { Não utilizar enceradeira } \\
\text { Escolher horáno de menor circulação da equipe }\end{array}$ \\
\hline Arrarjo fisico inadequado & $\begin{array}{l}\text { Pias com cuba pequena, respingando no piso } \\
\text { Ausência de canalização para drenagem de } \\
\text { hemodiálise, utilizando mangueiras } \\
\text { improvisadas } \\
\text { Portas sem identificação, sem visor e com } \\
\text { sistema de fechamento inadequado }\end{array}$ & $\begin{array}{l}\text { Trocar pias } \\
\text { Ligar encanamento direto para esgoto } \\
\text { Identificar as portas e instalar visores } \\
\text { Modificar tipo de abertura e fecharnento das } \\
\text { portas }\end{array}$ \\
\hline Tomada e ponto de antena insuficiente & $\begin{array}{l}\text { Preserça de extersões elétrica e fios de antena } \\
\text { pelo ambiente }\end{array}$ & $\begin{array}{l}\text { Aumentar o número de tomadas e adequar os } \\
\text { pontos de antena }\end{array}$ \\
\hline Ilưninação insuficiente & $\begin{array}{l}\text { Postos escuros, com iluminação natural e } \\
\text { artificial insuficiente }\end{array}$ & Melhorar a iluminação artificial \\
\hline Amazenamento de soro inadequado & $\begin{array}{l}\text { Prateleiras altas e semproteção, possibilitando } \\
\text { queda dos frascos e acidentes }\end{array}$ & $\begin{array}{l}\text { Colocar grades nas prateleiras } \\
\text { Usar escadas adequadas para acesso ao soro }\end{array}$ \\
\hline $\begin{array}{l}\text { Equipamento ultrapassado e com falta de } \\
\text { manutenção }\end{array}$ & $\begin{array}{l}\text { Monitores e focos com fio desencapado } \\
\text { Equipamentos grandes e pesados com } \\
\text { dificuldade de remoção }\end{array}$ & $\begin{array}{l}\text { Fazer manutenção preventiva } \\
\text { Substituir por monitores compactos e de fácil } \\
\text { remoção }\end{array}$ \\
\hline Inadequada eliminaçãoe tratamento do lixo & $\begin{array}{l}\text { Frascos com secreção no lixo } \\
\text { Lixo no chão }\end{array}$ & Orientar e treinar a equipe \\
\hline
\end{tabular}

Figura 7 - Classificação de riscos de acidentes (grupo 5: cor azul) apontados pelos trabalhadores de UTI, sua principal fonte geradora e recomendações, Campinas, São Paulo, 1998 


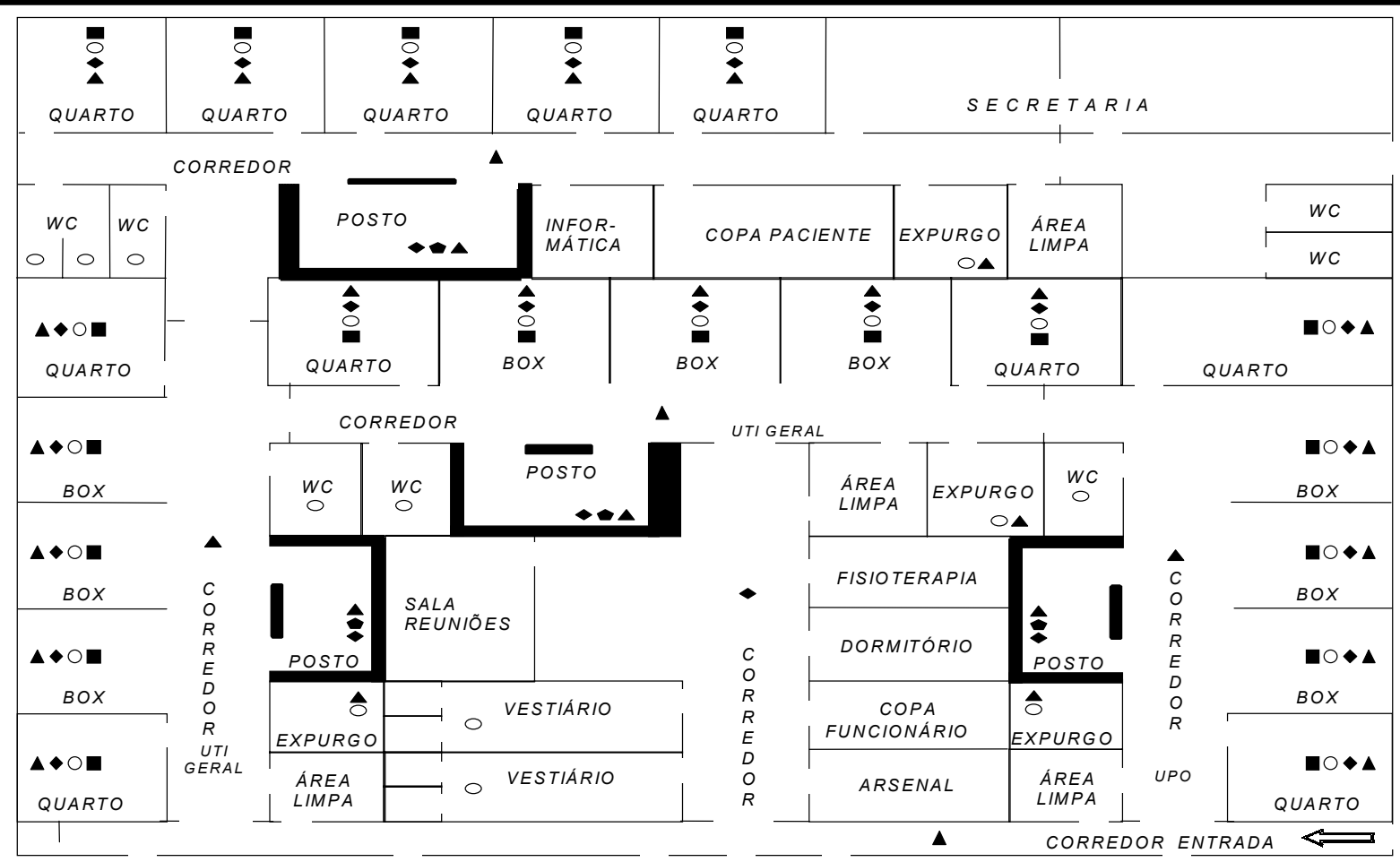

Legenda: $\nabla$ Riscos físicos Riscos Químicos $\bigcirc$ Riscos Biológicos $\square$ Riscos Ergonômicos $\Delta$ Riscos de Acidentes

Figura 8 - Mapa de risco da unidade de terapia intensiva, Campinas, São Paulo, 1998

\section{Riscos Físicos}

1. Temperatura instável e pouca circulação de ar

2. Radiação ionizante

Riscos Químicos $*$

3. Inalação de produtos químicos

\section{Riscos Biológicos}

4. Contato com fluidos corporais

5. limpeza e higiene dos sanitários

Riscos Ergonômicos 色

6. Esforço físico/postura não ergonômica

7. Atitude automática e ritmo excessivo

\section{Riscos de Acidentes $\star$}

8. Material perfurocortante

9. Chão molhado e escorregadio

10. Planta física inadequada

11. Tomada e ponto de antena insuficiente

12. Armazenamento soro inadequado

13. Equipamento ultrapassado

14. Iluminação insuficiente

15. Inadequada eliminação e tratamento do lixo

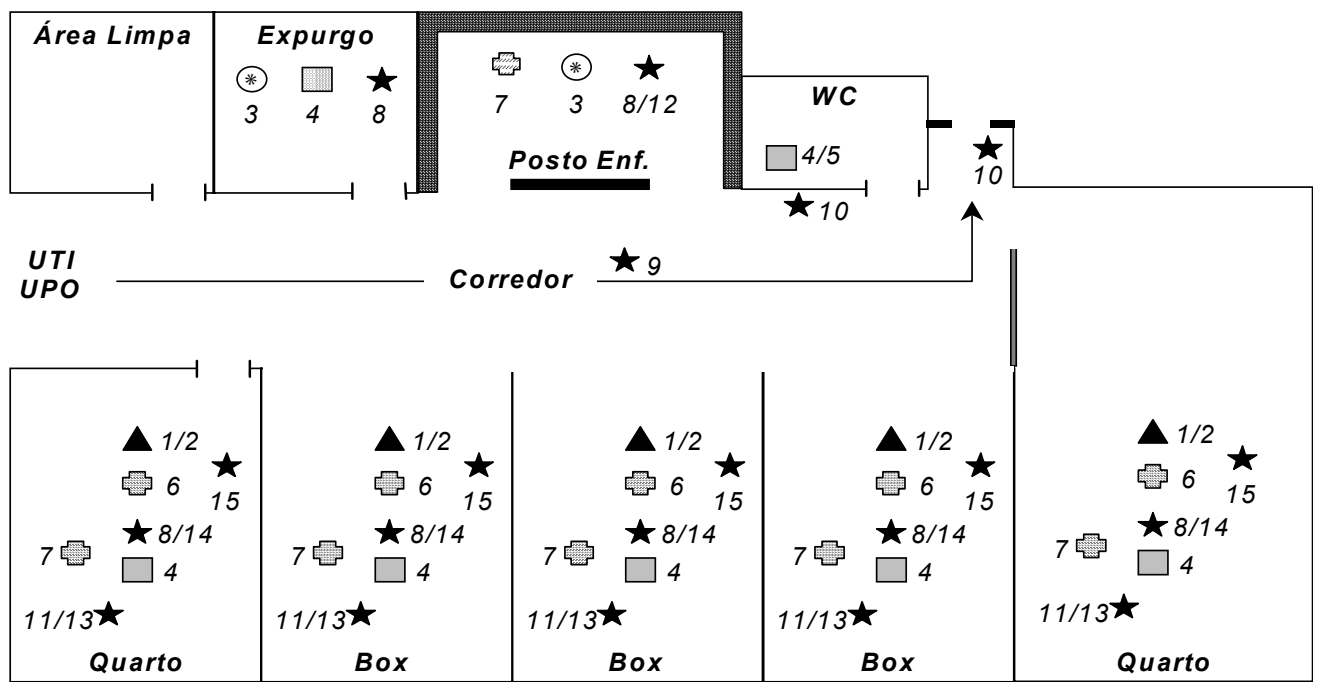

Figura 9 - Mapa de risco referente a Unidade Pós-operatória de Unidade de Terapia Intensiva, Campinas, São Paulo, 1998 


\section{CONCLUSÕES}

O presente trabalho revela a necessidade do estudo e elaboração do mapa de risco ambiental no âmbito hospitalar, não só para atender a legislação vigente (NR5), mas principalmente para prevenir, controlar e/ou eliminar os riscos de acidentes ocupacionais.
A importância de iniciar este estudo pela entrevista com o trabalhador é a de incorporar a visão do mesmo sobre os riscos ambientais existentes em seu diaa-dia hospitalar. Após a implantação do mapa de riscos e acompanhamento dos seus resultados, a metodologia empregada também será reavaliada pelas autoras.

\title{
ELABORATION AND IMPLEMENTATION OF ENVIRONMENTAL RISK MAP FOR PREVENTION OF WORK RELATED ACCIDENTS IN AN INTENSIVE CARE UNIT OF A UNIVERSITY HOSPITAL
}

This study has the objective to discuss some questions related to occupational risks that health professionals are exposed to in the Intensive Care Unit environment. A questionnaire was used, asking the health care workers to describe the occupational risks they know about. As a result, the participants indicated risks related to biological, physical, chemical, ergonomic and occupational risks.

KEY WORDS: occupational accident, occupational health

\section{IMPLEMENTACIÓN DEL MAPA DE RIESGOS AMBIENTALES PARA PREVENCIÓN DE ACCIDENTES DE TRABAJO EN UNA UNIDAD DE TERAPIA INTENSIVA DE UN HOSPITAL UNIVERSITARIO}

\begin{abstract}
El objetivo de este trabajo es traer para el ámbito de la salud del trabajador cuestionamientos relativos a los riesgos ambientales a que están expuestos los trabajadores de la Unidad de Terapia Intensiva. Para esto, se elaboró un instrumento, en el que dichos trabajadores describen los riesgos ambientales de su Unidad. Como resultado se comprobó en el ambiente la existencia de riesgos biológicos, físicos, químicos, ergonómicos y riesgo de accidentes de trabajo.
\end{abstract}

TÉRMINOS CLAVES: accidente de trabajo, salud trabajadores

\section{REFERÊNCIAS BIBLIOGRÁFICAS}

01. ALEXANDRE, N.M.C. Contribuição ao estudo das cervicodorsolombalgias em profissionais de enfermagem. Ribeirão Preto, 1993. 185p. Tese (Doutorado) - Escola de Enfermagem de Ribeirão Preto, Universidade de São Paulo.

02. BENATTI, M.C.C. Acidente do trabalho em um hospital universitário: um estudo sobre a ocorrência e os fatores de risco entre trabalhadores de enfermagem. São Paulo, 1997. 239 p. Tese (Doutorado) - Escola de Enfermagem, Universidade de São Paulo.

03. BRASIL. Ministério da Saúde. Secretaria de Saúde. Departamento de Normas Técnicas. Normas para Projetos Físicos de Estabelecimentos Assistênciais de Saúde. Brasília, 1995. p. 140.

04. CAMPOS, A. Cipa: Comissão Interna de prevenção de acidentes - uma nova abordagem. São Paulo: SENAC, 1999.

05. CARDO, D. Profissional de saúde deve ser cuidadoso sempre. /inf/. Soc. Bras. Infect., v. 3, n. 4, p. 3, 1995.
06. CARRASCAL, M.S.B. Infeccion V.I.H., transmisión horizontal. Rev. Rol Enfermeria, v. 14, n. 150, p. 60-2, 1991.

07. CONSELHO FEDERAL DE ENFERMAGEM (Brasil). Código de Ética: profissionais de enfermagem. Rio de Janeiro, 1993.

08. COSTA, M.R. da. As vítimas do capital: os acidentados do trabalho. Rio de Janeiro: Achiamé, 1981.

09. FRANCO, A.R. Estudo preliminar das repercussões do processo de trabalho sobre a saúde dos trabalhadores de um hospital geral. Ribeirão Preto, 1981. 217 p. Tese (Doutorado) Faculdade de Medicina de Ribeirão Preto, Universidade de São Paulo.

10. GIAMPAOLI, E. Temperaturas estremas. In: ASTETE, M.W.; GIAMPAOLI, E.; ZIDAN, L.N. Riscos físicos. São Paulo: Fundacentro, 1985. p.33-99.

11. GOMES, J. R. Saúde ocupacional no hospital. Rev. Paul. Hosp., v. 22, n. 6, p. 274-6, 1974. 
12. MACHADO, A.A. et al. Riscos de infecção pelo vírus de imunodeficiência humana (HIV) em profissionais de saúde. Rev. Saúde Pública, v. 26, n. 1, p. 54-6, 1992.

13. PITTA, A.M.F. Hospital: dor e morte como ofício. São Paulo: Hucitec, 1990.

14. SANTOS, W.D.F. dos et al. Acidentes típicos de trabalho em pessoal de enfermagem: fatores associados. Rev. Bras. Saúde Ocup., v. 17, n. 68, p. 38-42, 1989.

15. SEGURANÇA e medicina do trabalho. 43. ed. São Paulo: Atlas, 1999.

16. SILVA, A. et al. Estudo sobre os acidentes de trabalho ocorridos com a equipe de enfermagem em unidade de centro cirúrgico de um hospital geral. São Paulo. In: Congresso Brasileiro de Enfermagem em Centro Cirúrgico, 2, São Paulo, 1995. Anais. São Paulo: Sociedade Brasileira de Enfermagem de Centro Cirúrgico, 1995. p. 94-102.
17. SILVA, V.E.F. da. Estudo sobre acidentes de trabalho ocorridos com trabalhadores de enfermagem de um hospital de ensino. São Paulo, 1988. 176p. Dissertação (Mestrado) Escola de Enfermagem, Universidade de São Paulo.

18. SOUZA, M.; VIANNA, L.A.C. Incidência de acidentes de trabalho relacionada com a não utilização das precauções universais. Rev. Bras. Enfermagem, v. 46, n. 3/4, p. 234-44, 1993.

19. WEDEL, S. et al. Guidelines for intensive care unit desing: guidelines - pratice parameters Committee of the American College of Critical Care Medicine. Crit. Care Med., v. 23, n. 3, p. 582-8, 1995. 